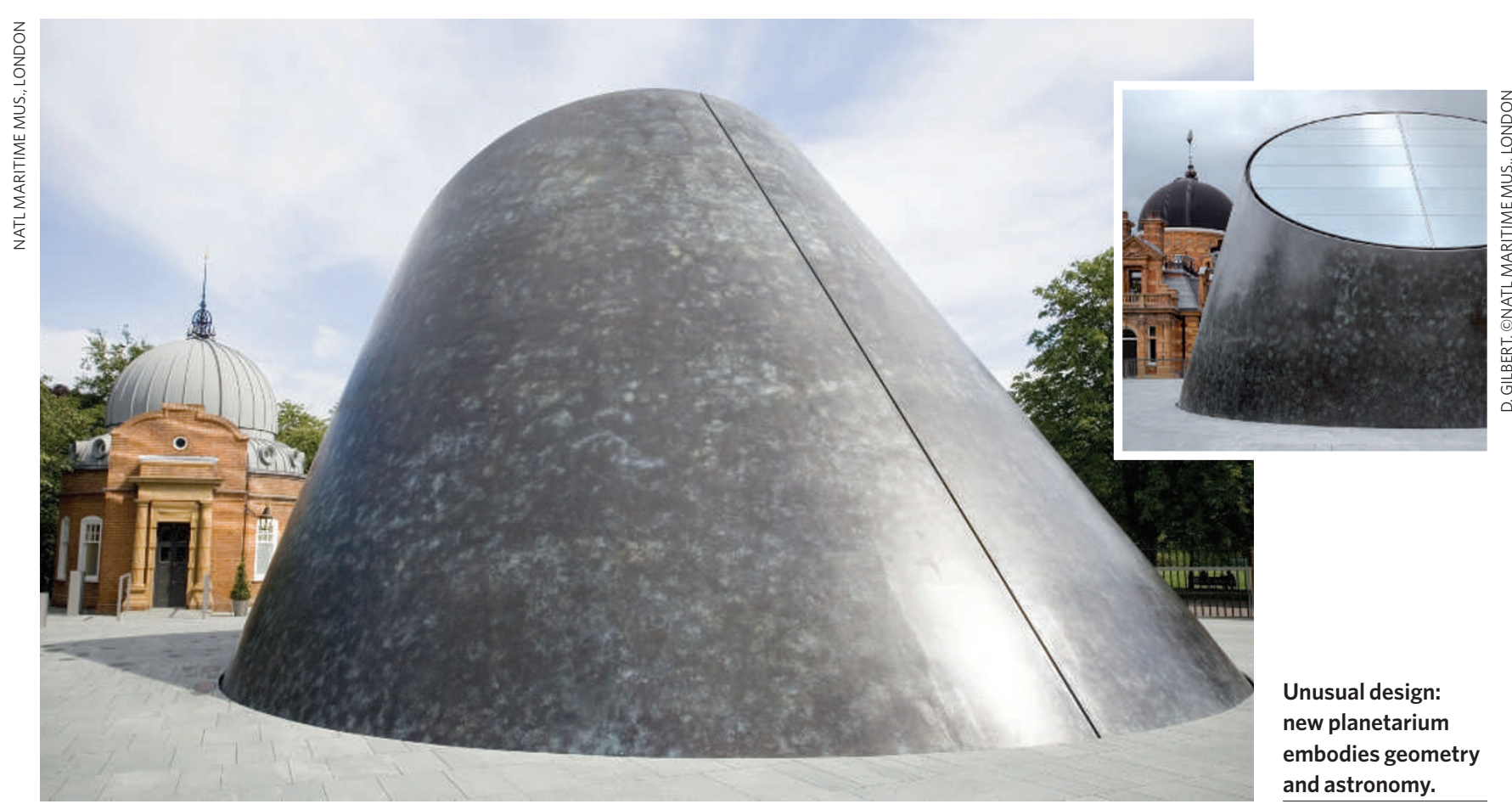

\title{
The clever cone
}

\section{A new planetarium for the Royal Observatory in Greenwich.}

\section{Martin Kemp \\ Traditionally planetariums have been} housed in domed structures, echoing the 'vault of the heavens'. As we approach the new Peter Harrison Planetarium at Greenwich, London, across the terrace overlooking the Thames, high above Inigo Jones's Queen's House and Christopher Wren's Greenwich Hospital, our expectations are confounded. A strange mottled bronze cone emerges from the paving, like the protruding tail of an alien space craft that has crash-landed, deeply embedding itself in the ground.

As we walk around the cone, its form progressively declares itself. One side is vertical, whereas the opposite contour emerges at an angle from the ground. The cone has been sliced to produce an elliptical face, mirrored to reflect the passing sky.

It transpires that the inscribed angle of the inclined face is $51.5^{\circ}$, corresponding to the latitude of Greenwich. The conic section is made at $90^{\circ}$ to this face, which means that the mirrored plane is parallel to the Equator. The vertical edge designates the zenith, while an inscribed line running up the sloping contour acts as a sighting line for the North Star.

This is an unquestionably clever building, which acts as visual and pedagogic compliment to the inscribed sphere of the 120 -seat internal viewing chamber. It has been designed by architects Allies and
Morrison as part of the $E 15$-million (US\$30-million) redevelopment of the historic complex of former Royal Observatory buildings.

The site is literally central to the history of the measurement of the world and of the cosmos, in keeping with the idea of "man as the measure of all things" (to quote the ancient tag credited to Protagoras). It was here in 1675 , by the decree of Charles II, that Christopher Wren built the observatory for John Flamsteed, with the express purpose of finding an exact way to determine longitude. The quest, as we know, was to be prolonged, and only in 1773 was John Harrison's H4 timekeeper recognized as providing the means to solve the problem.

The worldwide adoption of Greenwich Mean Time as the international point of reference was enshrined in 1884 with the recognition at the Washington gathering of 25 nations that the Greenwich meridian should henceforth be regarded as longitude $0^{\circ}$.

Looking at the Peter Harrison Planetarium in its historic setting, resonances abound. Not least, it is elegantly in keeping with the modes of thought that animated Wren, Robert Hooke and other luminaries of the early Royal Society. The immanent geometry of nature, whether the mighty ellipses of the planets or the miniature 'engines' revealed by the microscope, was not only the fit subject of science but also provided human designers with their basic vocabulary of form.

Conic sections and newly defined curves lay at the heart of Wren's work in architecture no less than in his science. He stressed that "the geometrical is the most essential part of architecture". By "geometrical" he meant not so much the abstract basis of beauty but the embeddedness of geometry in engineered structures, natural and artificial.

As an astronomer, student of dynamics and statics, meteorologist and inventor of scientific devices, Wren's practical extraction of natural design was perpetually at the heart of his endeavour. This understanding was expressed above in his domes, including the twin structures of Greenwich Hospital and, of course, that of St Paul's Cathedral.

Wren and his contemporaries would have been surprised by the actual form and materials of the new planetarium, which inevitably lie outside their architectural vocabulary of the seventeenth century, but they would have felt completely at home with the geometry and astronomy that it embodies. The new planetarium is a fitting addition to a site that demands architecture of a high order.

Martin Kemp is professor of the history of art at the University of Oxford, Oxford OX11PT, UK. His new book, Seen | Unseen, is published by Oxford University Press. 